\title{
DEVELOPING PARASITIC ARCHITECTURE AS A TOOL FOR PROPAGATION WITHIN CITIES
}

\author{
Daniel GIVEN (1D *
}

Independent Researcher

Received 25 February 2021; accepted 08 October 2021

\begin{abstract}
The term 'parasitic architecture' is an overused, and misunderstood buzzword within the architectural and urban planning community. By breaking down, through case study, how a space is developed and evolves, reclassification of architectural parasites is possible. Focusing on how parasitic architecture has produced urban growth and development of community within Tokyo as the primary case study, the reclassification is based in pre-existing architectural development and the nature of actual, living parasites. This reclassification of architectural parasite produces three separate types of parasite; the 'structured,' 'symbiotic' and the 'hyper transient.' Through the use of redefinition and reclassification, parasites in an architectural or urban planning context are then able to be manipulated as a tool for propagation within the existing built environment. Space within cities and megacities are becoming more of a commodity, so by utilising these new parasitic tools, it is possible to manipulate space to allow for an increase in urban growth, whilst still being flexible enough to fit into pre-existing planning legislation globally.
\end{abstract}

Keywords: parasite, parasitic, architecture, propagation, extensions, biomimicry, theory, orientalism.

\section{Introduction}

In 1966, Architect O. M. Ungers published 'Grossformen im Wognungsbau' (Large forms in residential construction), where he discussed the effects of fill-in architecture and quantified the use of informal and unplanned architecture. The adaption of this quantification lead to the term 'parasitic architecture' (Mühlthaler \& Ungers, 1966).

This term has since become a term synonymous with 'Extension' within architectural groups globally. The Collins Dictionary (2018) defines a building extension as a 'new room or building which is added to an existing building or group of buildings.' In comparison, parasitic architecture is defined by Lo (2017) as 'a building that is attached to an existing larger structure.' The issue is that they are often defined the same, but parasitic architecture is a more complex idea within the design world. The problems raised from the lack of distinction, is that the 'parasite' is being underutilised as a tool, and more as a disguise for visually unusual extensions, as well as the 'parasite' being used exclusively for the benefit of the singular 'host' structure; going against the biological definition of a parasite, as well as excluding any potential for exponential growth within the context of a city.
The goal of this paper is to develop an understanding of 'parasitic architecture, and how the use of these proposed developments could be used to propagate expansion within a pre-existing element of the built environment, such as housing, community or commercialism. With the current architectural understanding being a synonymity between 'extension' and 'parasite', there is no room for the development of a tool for architects and urban designers, and unless a change in verbiage is proposed, 'parasitic architecture' will remain a buzzword for unusual 'extensions.'

Whilst there have been attempts to approach parasitic architecture from a biological point of view by architects and engineers, such as Baroš and Katunský (2020), there has been no unified approach to the development of parasitic architecture as a tool for propagation within existing cityscapes. Due to this lack of development, and the use of the term 'parasitic' to evoke concepts of modernity over the simple 'extension,' there has been no major attempt to produce a concept for a working literary tool. By implementing an expansion on the term 'parasite' through biological means, and expanding towards existing parasitic and symbiotic organisms, achieving a working tool is within grasp. Within this paper, using two trainlines in Tokyo as case studies, the concept and foundation for a parasitical/symbiotic tool is to be explained.

${ }^{*}$ Corresponding author. E-mail: daniel_given@sky.com

Copyright $\odot 2021$ The Author(s). Published by Vilnius Gediminas Technical University

This is an Open Access article distributed under the terms of the Creative Commons Attribution License (http://creativecommons.org/licenses/by/4.0/), which permits unrestricted use, distribution, and reproduction in any medium, provided the original author and source are credited. 


\section{Methodology/theoretical framework}

This paper is the result of a research trip taken to Asia, predominantly to Japan and South Korea, in late 2019. With the premise of the trip to be the exploration of megacity development; the effects of parasitic architecture became notable when exploring the market spaces of Tokyo, but not in the traditional sense of an extension as mentioned previously, but more as an organism feeding off a pre-existing 'host.' As an example, 'Non-places' (a space of anonymous human transcience) as defined by Augé (1995), have been appropriated and converted through the use of parasitic architecture within the interstitial spaces left behind from the construction of the train lines. This has not only allowed for the perpetual growth of occupied space within the city, but has led to a point of economic development. Using Ameya-Yokochō (Figure 1) as an initial case study, the market acts as an organism feeding off the host site, Ueno Train Station. It is an example of how the use of an architectural 'parasite' can be used to propagate communities and commercialism within preexisting areas of a city. This example clearly demonstrates how through the development of a symbiotic connection to an existing hub allows for further urban development.

Through the understanding of Ameya-Yokochō, the creation of these parasitic/symbiotic elements, and how they interact within an existing cityscape has raised additional questions regarding whether this was a trend that could be spotted throughout the city, or whether this is a singular occurrence. By expanding the area of research, the parasitic element built upon 'Non-places' became more apparent. A notable example being the subway station at Asakusabashi Station, where, within the void spaces created below the track structure, spaces of commercialism were increasing.

Given the vertical nature of Japanese trainlines, the creation of void space is more noticeable when compared to trainlines built below ground. Due to the increased expense that comes with vertically constructed trainlines, both JR West \& JR East (Japan's leading rail companies) develop above ground trainlines in the most populated cities (Tokyo, Nagoya, Osaka \& Fukuoka). When comparing stations between Tokyo and Kyoto, there is a distinct lack of commercialism feeding off the movement of bodies within the areas surrounding the below ground tracks within Kyoto, when compared to the above ground tracks in Tokyo due to the increase in expense (Keiichiro, 2010). 'Ekinaki' (shopping centres within stations) are not accounted for below ground but are used within above ground trainlines as a form of financial recouperation. By contrast, the trains lines within Seoul, South Korea, are largely built below ground, but the 'commercial-parasite' is accounted for with the development of underground shopping centres, notably Myeongdong and Gangnam underground shopping centres.

By extrapolating the principles taken from AmeyaYokochō as a case study to the point of an observational qualitative research, the trends at which a 'parasite' can enhance and symbiotically exist within its surroundings become notable. Understanding that 'parasites' are inherently seen as a negative within nature, with positivity relating to biological symbiosis, developing and understanding the application of 'parasites' within a biomimicry sense, becomes key, the notable elements taken from the observational qualitative study become features of implantation, allowing for urban propagation within pre-existing built environments.

\section{Results of research}

Through visiting the areas that are being used as case studies within this paper, and exploring the ideas of parasitism being utilised, it was clear an understanding of the relationships between the 'host(s)' and 'parasites' was required. To allow for the development of categorisation and implantational methods of propagational 'parasites', a clear

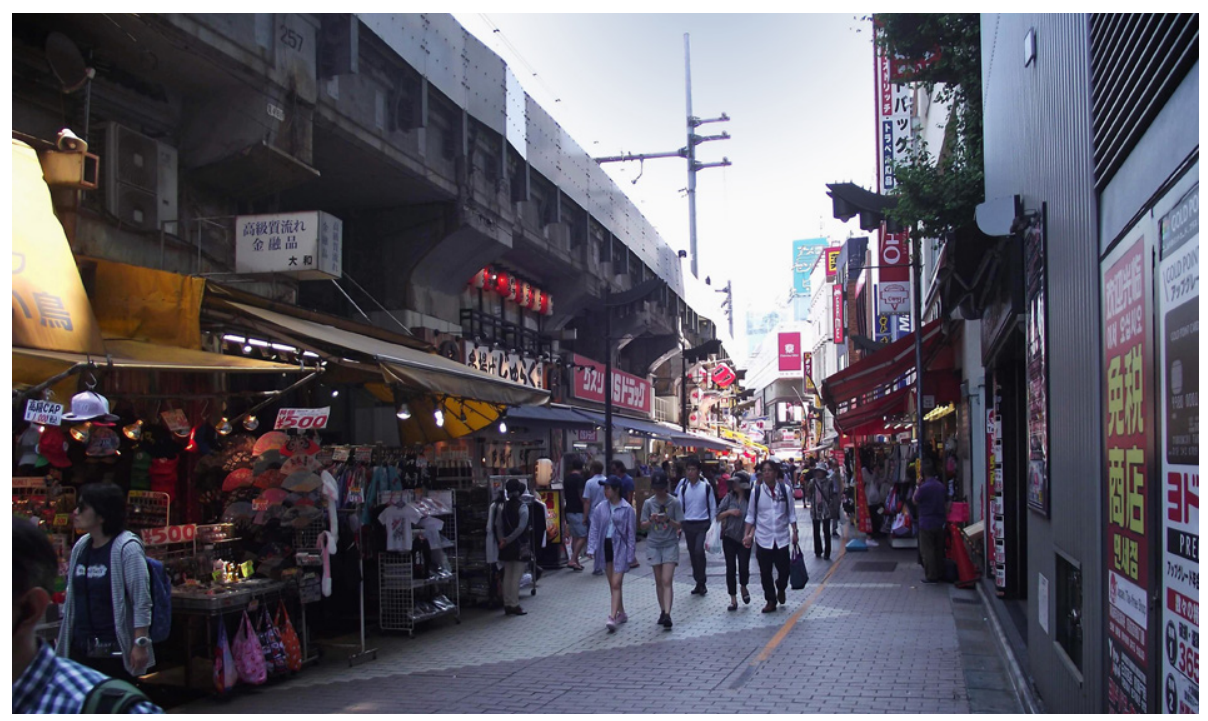

Figure 1. Ameya-Yokochō Street Market 
understanding of how the existing parasitical bonds are formed is required.

Ueno station was considered a primary hub of postwar movement following World War Two, with there being an influx of bodies moving through this space to and from the North of Japan (Covatta, 2017). The station itself is still considered one of the heavier transit hubs within Tokyo, with a large number of people passing through the station for inner city travel, as well as travelling to external destinations. As an above ground transport line housed within a singular building with a singular purpose, situated in a city of increasing density, the new organism would need to grow into the residual spaces. It would still need to maintain a close enough distance to the original source of bodies, as to fully capitalise on and maximise interaction with the bodies. Whilst it could be argued that the market space of Ameya-Yokochō is more akin to fill-in architecture (Gürcan, 2018) as opposed to inherently parasitic. The noticeable symbiotic relationship between the market and the station (Figure 2) indicates that without the 'host,' the 'parasite' would be unable to propagate within the provided space, whilst simultaneously causing an increase of bodies moving through the host to arrive at AmeyaYokochō. With parasitism, it is expected that the 'parasite' is the sole beneficiary of the relationship, but given the positive connotations of the relationships developed off of Ueno Station, neither host, nor 'parasite' are the sole beneficiary. As such, there is a dichotomy between a parasite and a symbiote. 'Parasite' having a negative connotation, having a sole beneficiary and 'symbiote' being positive, with a mutually beneficiary relationship.

The space that makes up the Ameya-Yokochō Market, whilst considered parasitical, can also be considered to be a collection of smaller parasitic elements working in

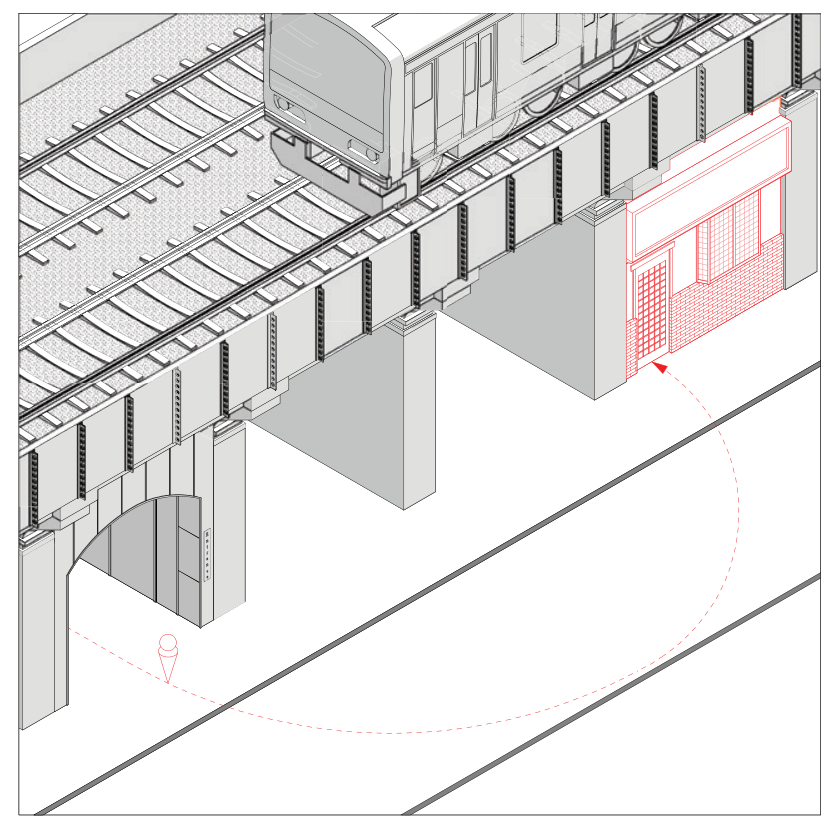

Figure 2. Relationship of host and the parasite through movement patterns symbiosis with the station. This relationship is a product of a void, with profit becoming the beneficial outcome of the symbiotic relationship. With Ameya-Yokochō, what makes the market symbiotic, as opposed to a generic selection of stores on a street, is a result of its history. Alongside an influx of bodies to Ueno Station after World War Two also came the need and want for goods. As such, the area below and around the tracks was considered a place suitable for a black market, where American goods and candy could be sold. If products are being sold illegally, the option of setting up an official store becomes an issue, and as such, a quick pop-up market becomes the only option. With the symbiosis between both the 'host' and the organisms beginning to feed inherently off one another, the potential for the government of Tokyo to be able to gain capitalistically off the market space would have been brought to light. Through the changing of laws regarding what could be sold legally, as well as the gentrification of the black market, selling and renting of the land below the tracks to the original stall owners allowed the government to 'feed' though the charging of rent.

This relationship between transport hub and commercialism is a common site within Tokyo, with another notable example being the train line leading into Asakusabashi Station. The relevance of this is due to the construction that was witnessed during the research trip to Japan. Adding to the idea that the under-track complex is parasitical in nature is the evidence of the existing trainline arches acting as a feasible architectural framework to stitch commercialism into. The now commercial spaces below the Asakusabashi tracks are a seemingly dissonant combination of structures, with there being variations of connectivity to the existing framework. Where some stores are seemingly pop-ups 'sheltering' below the tracks, others have fully integrated themselves into the structure, having permanent utilities outfitted through the structure, and betwixt the existing foundations of the archways. An example of this phenomenon was the construction work beneath Asakusabashi trainline. The construction work being undertaken was to not only ensure structural safety and meeting of building regulations, but the foundations being underpinned to the existing support structure of the trainline would ensure that the parasite was permanently affecting the host.

The key difference between Ameya-Yokochō Market and the commercial spaces of Asakusabashi lies in the relation to the other 'parasites.' The market 'parasites' are all inherently the same, working from the same background and developing from illegality to legality, whilst at Asakusabashi, the stores and restaurants have attached themselves to the station for the sole purpose of feeding off the supplied bodies. As discussed previously, the difference between 'parasite' and 'symbiote' become apparent when comparing Ameya-Yokochō Market and Asakusabashi Station. One notable difference is the presence of bars and izakaya located around the entrance/exit of the trainline. Where the development of propagation lies within the area surrounding the Asakusabashi line is in the act of becoming a point of destination. When first observing the station during the 


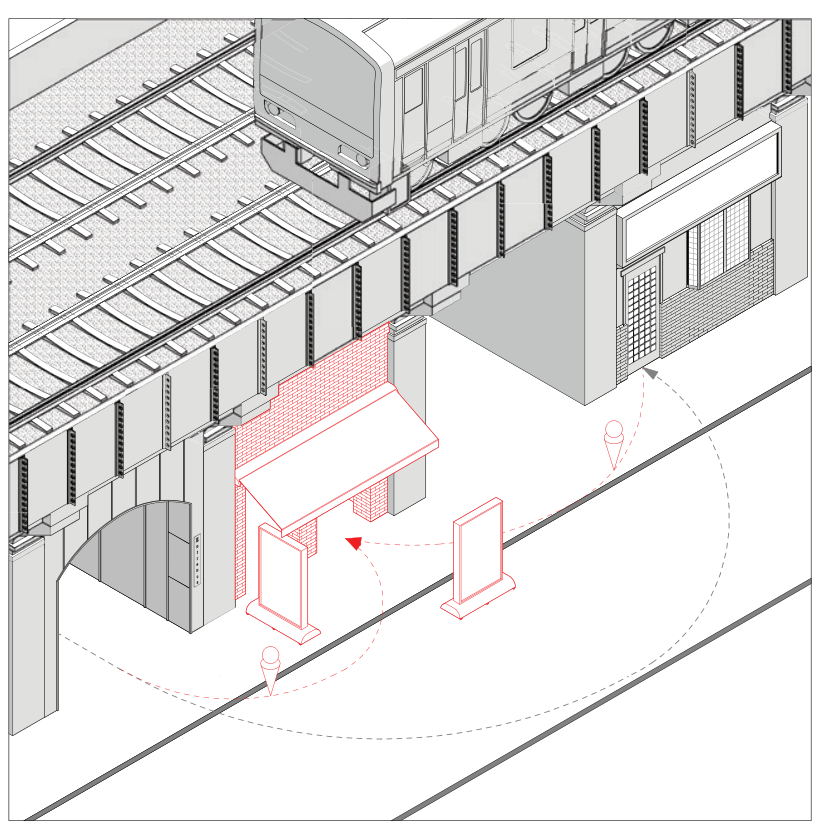

Figure 3. Parasites produce new movement patterns from existing relationships

evening rush hour, a large amount of people who exited the station automatically moved towards the stores, restaurants, bars and izakaya, before assumingly, making their way home. To ensure that the assumption was not only an occurrence during rush hour, observations were made during the times that the 'destination parasites' were open. What was found is that there was a consistent stream of patrons to these businesses through all hours of the day.

Outside of this parasitism, there was also a considerable number of parasitic stores feeding off of the bodies moving between Asakusabashi station and the 'destination parasites.' These stores were located between the points of destination and the entrance to the 'host' (Figure 3), with the only relation to either being proximity. Whilst witnessing bodies move between the host and a 'destination parasite', it was common to see them window shopping through these secondary 'parasites', and occasionally entering and making purchases. As mentioned earlier, this kind of parasitic nature can be more cohesively planned for and could easily be compared to other types of parasitic commercialism such as the underground shopping centres of Seoul.

With the site below Asakusabashi Station still open to development, and a number of the voids below the trainline currently being used as car parking spaces, there is still potential for the propagation of commercial space, whether based in destination and symbiosis, or just parasitically feeding off the existing relationships. This potential creates the possibility of planning for propagation and formation of a 'forced' destination, depending on the planning of the area. The result being an economic boon in the area and an increase in the number of bodies potentially moving through Asakusabashi Station. Tokyo has precedent for this kind of developed parasitism, with a number of areas like the two mentioned above producing complex propagation within the city. As such, there are key elements that have the potential to be manipulated to allow the criteria to become transferable to, not only Japanese streets, but streets within other sizeable cities.

\section{Discussion/interpretation of results}

As touched upon previously, there are several key factors that apply when instigating propagation and development within a pre-existing context. What can be taken from understanding spaces such as Ameya-Yokochō Market and the developing space below Asakusabashi Station are three key ideals for potential parasitical developments:

\subsection{History and development of site}

Ameya-Yokochō developed from a need for the black market to conform to the legality within Tokyo. This idea that the 'parasite(s)' formed from a necessity to ensure its own survival can be considered the key point of parasitical development for the market. When trying to relate this as a potential tool for propagation and how a space can be shifted and fundamentally developed, an understanding of the future space and the extrapolation of the existing program is key. In this sense, a governmental overhaul plays a greater part by defining the terms of requirement. In the case of Ameya-Yokochō, the transition from thrown together black market to developed property came from regulation by the Tokyo planning office, initially through the development of twelve separate companies, forming the Naka-Okachimachi Wholesalers' Association (Brazil, 2004). This same effect of legal, urban planning-based coercion has also been witnessed globally (to a greater degree within developed city states).

In this sense, a governments role in the development of architectural 'parasites' is two-fold:

1. Is the 'parasite' pre-existing and needs to be brought into line with current planning legislation and law?

2. How can the government/council profit from the development and propagation of the 'parasite'?

Ameya-Yokochō acts as a prime example to meet the first governmental role. A need for legality required the government/council of Tokyo to take time to develop an area correctly ${ }^{1}$, thus the site is developed further. For a government/council this development can be considered a longer-term investment, given the eventual payment from rent upon the land that is developed.

This act of a governmental development is less seen nowadays given the lack of illegal markets that are produced within developed cities. Whilst this isn't to say that it doesn't happen, a governments priority may lie elsewhere, with different requirements for land. Again, using a trainline as an example, the development of residential space was the most unlikely use of space given the nature

\footnotetext{
1 The term 'correctly' is used here in relation to urban planning and architectural legislation within Tokyo. As countries have their own rules and regulations, the term 'correctly' is used as an overarching term of development within a city.
} 
of the site, but this does not mean that the development of the site is a purely commercial endeavour.

The development of residential space is likely to happen within already heavily developed areas of the city, with residencies taking precedent within select districts of a city, such as key economical hubs for example (Noone et al., 2011). With an increase in economic activity within a city, comes with an increase in workers moving from rural to city to capitalise on the increase in work. Following the Alonso-Muth-Mills model, increased work in central business districts leads to increase in a need to remove the commute (Kulish et al., 2012), thus the development of small, expensive residencies. Parasitic residential space is less likely to be in the form of individual residence, but more likely to be in that of an apartment block in order to capitalise on the number of bodies living within one space. This is again likely to be within a short distance of a transport hub as to prioritise the movement to and from work, or within an area of natural beauty. Whilst not unfeasible, the development of residential properties moves away from commercial spaces unless specifically tied to said commercial space. It can be assumed that an apartment above a convenience store is the place of residence of the owner and has formed symbiosis with the commercial space through a shared body.

\subsection{Destination}

Initially a proposed development may not be considered parasitical, but from a different point of view, the act of feeding off the movement of bodies is an inherently parasitic act. In this sense, it could be deemed that every building or establishment within a city is considered a 'parasite' or 'symbiote' in the grand scheme of things; and in some respects that is true. But when regarding the propagation and development of spaces within a city, creating a point of destination implies an understanding of not only requirements of the governmental/planning legislation, but also the ability to extrapolate the movement of bodies to and from a space.

Using The Shard as an example; The Shard acts as the 'host' in this scenario, but has the same symbiotic relationship with London Bridge Station that Ameya-Yokochō has with Ueno Station. Living within The Shard are several 'symbiotes' that have developed within pre-planned spaces (feeding off of The Shards tourists, whilst paying rent and attracting guests to The Shard). Two of these 'symbiotes' are high-end, award-winning restaurants (Aqua Shard \& Oblix), and are destinations within their own right. Surrounding the area, feeding off the bodies travelling to these destinations ${ }^{2}$ are a number of stores, coffee shops

\footnotetext{
2 To further this point, The Shard, Aqua Shard and Oblix are not the only destination points of interest in this area of London; there are a number of points that people travel to, including areas of Kings College London and Guys Hospital. The Shard was used as a well know destination point that is known globally.
}

and hotels. These smaller 'parasites' exist purely to feed off the tourists moving through the space, whilst not giving back to the 'host' developing a micro community surrounding The Shard and London Bridge Station.

\subsection{Symbiosis}

Symbiosis of parasitical architecture is the next stage in the relationship of 'host' and 'parasite.' As seen with both Ameya-Yokochō, as well as the inner workings of The Shard, the relationship between the spaces has become beneficial to both parties. As mentioned with the area surrounding The Shard, the development of parasitical architecture that leads to a destination point follows a trend of creating a relationship with movement space, as discussed in relation to Asakusabashi Station. As such, the influx of bodies between the two or more 'organisms' allows for further feeding, with 'parasites' (sole beneficiary relationship) developing into 'symbiotes' (multi-beneficiary relationship), leading to organisms feeding off of the symbiotic relationships' movement, and the growth of 'hyperparasites' (Gleason et al., 2014). This hyperparasitism within an architectural or urban planning sense can be consider propagation and development of an area, with the cycle of one-sided benefits, developing into symbiotic relationships beginning anew.

As seen with the area surrounding The Shard, visitors to the site are fed upon through the development of coffee shops and commercial stores constructed in the vicinity of the symbiotic relationship purely to financially gain off this pre-existing connection. In some cases, the symbiotic relationship develops to allow for multiple, interconnected symbiotic relationships, thus producing more 'hyperparasites', and increasing the fundamental growth of an area. In another sense, a symbiotic relationship with 'hyperparasites' can lead to the development of communities, and to this, residential property is developed and feeds parasitically off the area as opposed to an individual 'host.'

\section{Explanation}

Inherently, parasitic architecture is an underutilised form of architecture, with the term 'architectural parasite' acting more as a buzzword for attention or a redefinition of an extension, as opposed to an actual tool possible for the development of existing cityscapes.

As mentioned earlier, there are a number of examples around the globe that utilise a form of parasitism. To ensure a lack of stagnation within urban development, producing parasitical and symbiotic relationships acts as a gateway to further development. Through the creation of destinations, and the subsequent 'hyperparasites' feeding off the new relationships, propagation of an area is enabled, and becomes cyclical. Small time urban planning development is then opened, with the nature of 'parasites' and the capitalistic need to become the 'best' in an area, subsequent destination points are created, and thus the cycle of development begins anew. 
To allow for the propagation of smaller inner-city connections, urban planners and architects need to consider the potential relationships between existing and proposed developments. Whilst this is already done through the restrictions as laid out within planning regulations, the extent at which one looks at the prospective relationships with the future is not fully considered unless the development is for a full reurbanisation project. As such there are four forms that an architectural 'parasite' can take on as discussed below.

\subsection{Architectural parasite}

An 'architectural parasite' is an independent structure that is the sole beneficiary from a constructed relationship. Architectural parasites inevitably lead to one of three outcomes:

- Dying out due to changes in supply and demand.

- Killing off the host structure.

- Developing a symbiotic relationship with the host.

\subsection{Architectural symbiote}

The 'architectural symbiote' acts as a closed loop relationship between 'host' and 'parasite.' An example, other than Ameya-Yokochō, being a coffee shop within a department store. The coffee shop feeds off the moving bodies within the 'host' store, whilst simultaneously paying rent for the space within. This closed loop system finds mutual benefits between both organisms, with no potential for expansion.

\subsection{Transitional parasite}

The 'transitional parasite' can be considered the halfway organism between a 'parasite' and a 'symbiote.' The relationship of the 'host' and the 'symbiote' is more structured and considered stable, with both organisms feeding off the movement of bodies within and between the space, but not quite to the point where they are both mutually beneficial between one another.

Due to the significance that the symbiotic relationship plays, this builds on the idea that destination is one of the key elements in urban parasitical development. With the nature of Ameya-Yokochō naturally forming a point of destination through post-war movement, the black market benefited from the bodies moving through the space, and the 'host' benefited from this subsequent development, thus forming the stable relationship that we see today.

It wasn't until the 'legalisation' of the market that the role of destination became prominent, with there being no negative side effects for the bodies feeding the 'parasite' and 'host.' As such, there was a boon in bodies travelling to and from the space, leading to the growth of the 'parasite.' Furthermore, this growth pushed the point of destination further to the point of becoming an active tourist hub. This cycle of growth continues; the 'parasite' grows, which in turn causes the 'parasite' to grow further into a 'transitional parasite, and further into a 'symbiote.'

As such, a 'transitional parasite' can be considered to cover two stages of parasitic organisms; the feeder and the destination. The feeder being the 'parasite' that is inherently developed over a vast increase of bodies, and the movement within a space. In this sense, the pre-legalised Ameya-Yokochō can be considered a feeder parasite, gaining from the influx of bodies at Ueno Station. The Destination being the natural progression of the feeder 'parasite, becoming an objective for the bodies in the area. Once the 'destination parasite' has reached an adequate size, and the influx of bodies has become stable, symbiosis is achieved through the evolution of the relationship with the 'host.'

However, symbiosis can only be achieved if the relationship between 'host' and 'parasite' is stable, otherwise the risk is that one will inevitably kill the other:

The 'host' remains dominant, and the 'parasite' never fully develops into a point of destination, and ultimately dies, without impacting the 'host.'

The parasite develops into a destination that ultimately becomes larger that the 'host', with the roles reversing. The original 'host' then proceeds to die as its own development never accounted for this change, and is ultimately unadaptable.

\subsection{Hyper transient parasite}

'Hyper transient parasites', unlike in nature, are not parasitic to a pre-existing parasitic organism. In the sense of urban and architectural development, a 'hyper transient parasite' feeds inherently on the flow of bodies that are produced through the creation of a symbiotic relationship.

The 'hyper transient parasite' could be considered the next stage of using parasitic development as a tool for propagation. With the 'transitional parasitic' relationship shifting to one of 'host' and destination, a secondary flow of bodies is produced, which for all intents and purposes, is available to feed additional organisms (Figure 4).

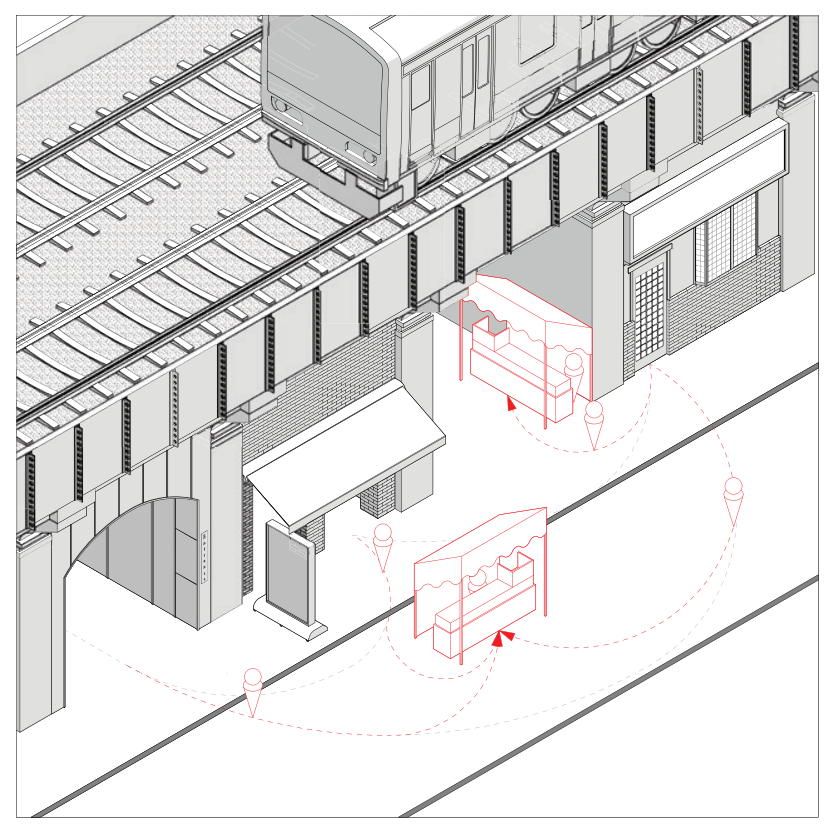

Figure 4. 'Hyper transient parasite' feeds of off the development of movement between the original host and the 'destination parasite' 


\section{Conclusions}

Through the act of research and elaborating on the definition of 'architectural parasite' there is an implicit relationship between parasitic propagation and the development of commercial spaces; with the primary 'food' not only being the bodies moving through the space, but more importantly, the money that moves with the bodies. Consequently, the urban development produced by parasitic relationships becomes one of feeding.

There is an innate belief within the construction industry that architectural 'parasites' are solitary organisms, more so when the term 'architectural parasite' is used as a buzz word, but the truth lies in the fact that the relationships between 'parasites' and 'hosts' is far more complicated than one structure grafted to another. A prime example of a multi-parasitical relationship is the Urban Hive Building in Seoul, South Korea (Figure 5). The building is a collection of offices and coffee shops built above an underground mall, which itself is built above an underground subway station. Whilst the 'hosts' of The Urban Hive (Sinnonhyeon Station and the offices) are only tenuously connected by the thoroughfare of foot traffic, the combination of 'transitional parasites', 'hyper transient parasites' and 'architectural symbiotes' fill the space between the two.

The relationship within and under The Urban Hive building also goes to demonstrate the idea that these parasitical relationships are not innately horizontal in nature. The ability to move through a space is not solely on

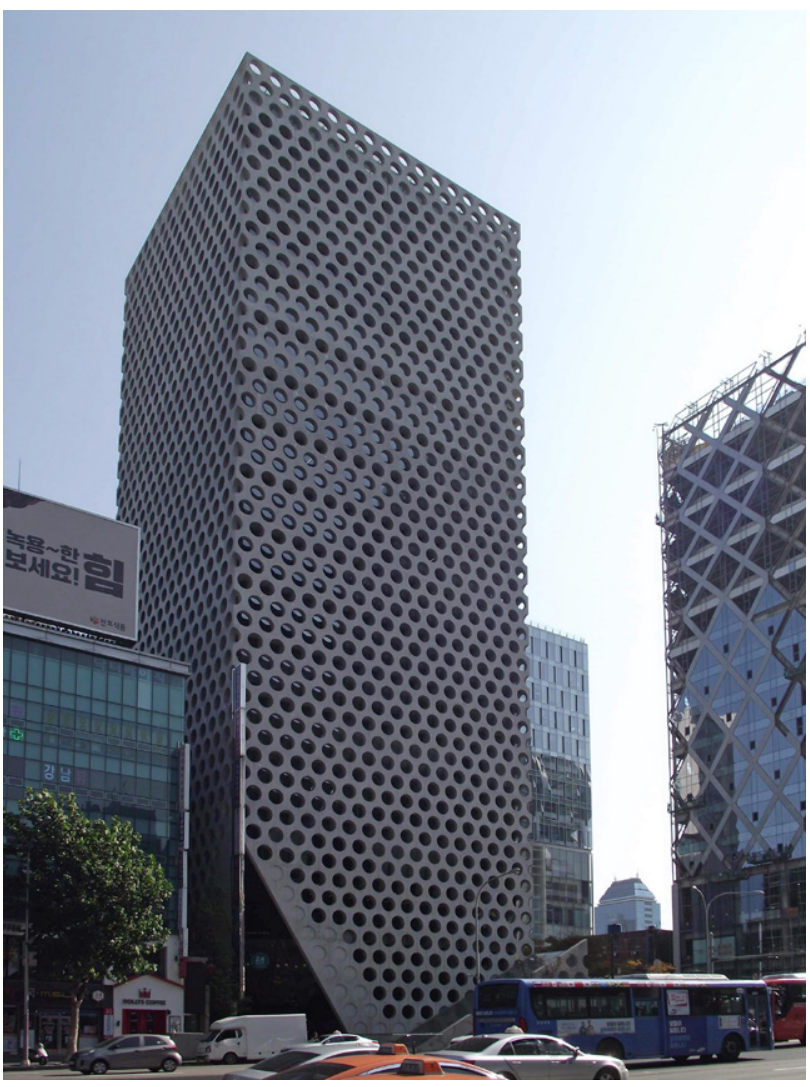

Figure 5. The Urban Hive building, Seoul, South Korea a single plane, with bodies being able to shift horizontally and vertically. The use of 'parasites' may allow for urban planners and architects to propagate, not only the ground, but through the development of space below ground, as seen with the below ground market spaces of South Korea and Japan, as well as above ground as seen with the proposed Sky Market in London (Bayley, 2020).

By shifting the term 'architectural parasite' from a buzzword used to explain one structure grafted to another, to a term which can be used as a tool for propagation, long term planning within a city space would become more cohesive. Architects and urban planners could use a parasitic understanding to allow for future development within a city, instead of planning for the use of a single building over a twenty-to-fifty-year span. The potential cohesion could see further development within an existing cityscape and avoiding stagnation and possible standstills in architectural evolution. As has already been seen within areas of the globe, such as Ameya-Yokochō, this will allow for not only a boon in commercialism, but also for identity and culture.

\section{References}

Augé, M. (1995). Non-places: Introduction to an anthropology of supermodernity (1st ed.). Verso.

Baroš, T., \& Katunský, D. (2020). Parasitic architecture. Journal of Civil Engineering, 15(1), 19-28.

https://doi.org/10.1515/sspjce-2020-0003

Bayley, S. (2020). What exactly is the 'sky market' that could be built above Tooting Broadway [online]. MyLondon. https:// www.mylondon.news/news/south-london-news/look-upamazing-plans-sky-18674120

Brazil, M. (2004). Okachimachi history [online]. Japanvisitor. https://www.japanvisitor.com/history/okachimachi-history

Collins Dictionary. (2018). Extension (countable noun) [online]. Collins. https://www.collinsdictionary.com/dictionary/english/extension

Covatta, A. (2017). Tokyo playground: The interplay between infrastructure and collective space. Université de Montréal.

Gleason, F., Lilje, O., Marano, A., Sime-Ngando, T., Sullivan, B., Kirchmair, M., \& Neuhauser, S. (2014). Ecological functions of zoosporic hyperparasites. Frontiers in Microbiology [online]. https://doi.org/10.3389/fmicb.2014.00244

Gürcan, B. (2018). Mutualistic understanding of fill-in architecture. Delft University of Technology.

Keiichiro, A. (2010). Breakthrough in Japanese railways 5: Japan's rail stations. Japan Railway \& Transport Review, 56, 31-35.

Kulish, M., Richards, A., \& Gillitzer, C. (2012). Urban structure and housing prices: Some evidence from Australian cities. Economic Record, 88(282), 303-322.

https://doi.org/10.1111/j.1475-4932.2012.00829.x

Lo, A. (2017). Why are designers creating parasite architecture? [online]. CNN Style. https://edition.cnn.com/style/article/ parasite-architecture/index.html

Mühlthaler, E., \& Ungers, O. (1966). Großformen im Wohnungsbau. Technical University of Berlin, Lehrstuhl für Entwerfen und Gebäudelehre.

Noone, P., Klompmaker, G., \& Sumanik, C. (2011). The high life: Residential towers in central business districts. CTBUH Journal, (2), 36-41. 